\title{
Sociodemographic Profile of Thyroid Masses: A Cross-Sectional Study
}

\author{
Basumatari Bharati ${ }^{1}$, Borah Pollov ${ }^{2}$, Mahanta Putul $^{3}$, Hazarika Devid ${ }^{4}$ \\ ${ }^{1}$ Assistant Professor, Department of Radiology, Fakhruddin Ali Ahmed Medical College and Hospital, Barpeta- \\ Jania Rd, Joti Gaon, Assam 781301, ${ }^{2}$ Associate Professor of Anaesthesia, Jorhat Medical College, Jorhat, Assam, \\ India, ${ }^{3}$ Professor of Forensic Medicine, ${ }^{4}$ Assistant Professor of Surgery, Assam Medical College, Dibrugarh, \\ Assam, India
}

\begin{abstract}
Introduction: Thyroid gland is the most superficial endocrine gland of the human body in the region of the neck and is easily accessible to both clinical and Radiological examinations. The thyroid masses must be diagnosed and managed as early as possible to avoid any malignancy.

Objectives: To evaluate the socio-demographic profile of patient including age and gender distribution in thyroid lesions.

Materials and Method: This prospective study was a cross-sectional descriptive one, which was conducted over the 50 subjects with thyroid masses. The collected data were subjected to a statistical analysis which was performed using a Statistical Package for the Social Sciences (SPSS) software version 20.0. Descriptive statistical method were computed, and the statistical significance was tested by chi-square test and student's t-test. A p-value of less than 0.05 was considered statistically significant. Ethical clearance was taken from ethics committee $(\mathrm{H})$.

Results: There was a female preponderance of $70 \%$ associated with this disease entity, against its male counterpart as $30 \%$. The male to female ratio is $1: 2: 33$. A maximum number of patients in our study is in the age group of 31-40 years of age, i.e. $40 \%$. Most of the patients $(76 \%)$ are from a rural area.

Conclusion: Female preponderance of thyroid masses in the age group of 31-40 years was observed and was more in rural areas. The sociodemographic profile is useful for better future planning of the management of thyroid masses.
\end{abstract}

Keywords: Female preponderance; young age group; rural involvement.

\section{Introduction}

The thyroid gland is the most superficial endocrine gland of the human body in the region of the neck. It is easily accessible to both clinical and radiological

\section{Corresponding Author:}

Hazarika Devid

Assistant Professor of Surgery, Assam Medical College, Dibrugarh, Assam, India

e-mail: drdevidgme@gmail.com examinations. It plays a vital role not only in the regulation of various metabolic activities of our body but also has an important role in controlling the heart rate, cardiac output and skeletal growth. Thus, the thyroid abnormalities like thyroiditis, thyroid nodule, goitre and malignancy must be diagnosed and managed as early as possible. ${ }^{1}$

Thyroid nodules are extremely common, found at palpation in $4 \%$ to $7 \%$ of an asymptomatic population, ${ }^{2}$ in $17 \%$ to $27 \%$ of cases at USG, ${ }^{3-5}$ and in $50 \%$ of cases at autopsy. ${ }^{6}$ 
It has been very fascinating and challenging for a clinical radiologist to evaluate the thyroid gland and diagnose the thyroid pathologies.

In a study, out of the 70 patients who had thyroid diseases, the author reported $78.5 \%$ females and $21.4 \%$ as males. Maximum numbers of patients in the age group of 41-50years were also reported in the same study, accounting for $35.7 \%$ of the cases. ${ }^{7}$

Thyroid nodules are 4 times more common in women than men and their frequency increases with age and low iodine intake. ${ }^{\mathbf{8}}$ The gender disparity is perhaps explained by the hormonal influences of both estrogen and progesterone, as increasing nodule size and new nodule development have been demonstrated to be related to pregnancy and multiparity., ${ }^{9,10}$ Exposure to ionizing radiation, either during childhood or as occupational exposure, will cause a rate of development of thyroid nodules of $2 \%$ per year, reaching a peak incidence in 15 to 25 years. ${ }^{\mathbf{1 1 , 1 2}}$

Clinically thyroid diseases present as painless gradual swelling of the neck. Sonography is only one of several diagnostic method for use in the evaluation of thyroid diseases. Sonography imagings determine the morphology, the level extent of the masses and lymphadenopathy at different levels.

There are several sociodemographic factors which may cause the thyroid to become enlarged. A diet deficient in iodine can cause goitre but this is rarely the cause because of the readily available iodine in our diets.

A combination of clinical assessment and radiological examination provides an accurate diagnosis in the wide majority of cases. However, the sociodemographic profile of the cases is also important in managing these cases. This paper aims to evaluate the sociodemographic profile of the thyroid masses.

\section{Materials and Method}

This study was a cross-sectional descriptive one, which was conducted in the Department of Radiology with the help of the department of pathology at Gauhati Medical College Hospital. A total of 50 subjects were subjected to this research. All the patients were selected from outpatient departments and indoor wards of various departments (mostly from ENT \& Surgery
department).A thorough clinical examination was done in all the cases and the data were recorded accordingly in predesigned pre-tested proforma.

Finally, the sociodemographic data were subjected to a statistical analysis which was performed using a Statistical Package for the Social Sciences (SPSS) software version 20.0. Descriptive statistical method were computed, and the statistical significance was tested by chi-square test and student's t-test. A p-value of less than 0.05 was considered statistically significant. Ethical clearance was taken from ethics committee $(\mathrm{H})$.

\section{Results}

The present study is an analysis of the sociodemographic profile of subjects having thyroid swelling. Initially, 62 patients of thyroid swelling were taken for study. Out of that, 50 cases were taken for study because other 12 cases the adequate amount of aspirate cannot be obtained.

Sex distribution pattern: It is evident from Table 1 and Figure 1 that there was a female preponderance of $70 \%$ associated with this disease entity, against its male counterpart $30 \%$. The male to female ratio is $1: 2: 33$.

Table 1: Sex wise distribution of the cases

\begin{tabular}{|l|c|c|c|}
\hline Sex & Number & Percentage (\%) & Ratio (M/F) \\
\cline { 1 - 3 } Male & 15 & 30 & \multirow{2}{*}{$1: 2: 33$} \\
\cline { 1 - 3 } Female & 35 & 70 & \\
\hline
\end{tabular}

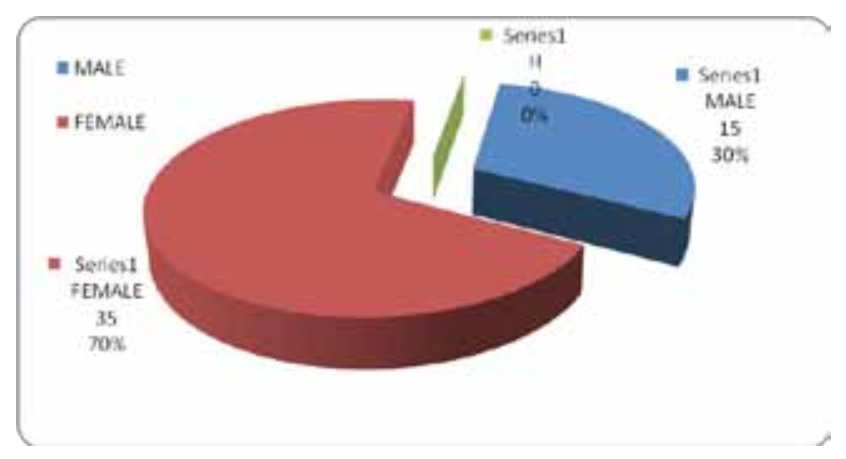

Figure 1: Sex wise distribution of the cases

Age distribution of the patients: A maximum number of patients in our study in the age group of 3140 yrs of age i.e. $40 \%$. There is no case recorded below $10 \mathrm{yrs}$ and above $70 \mathrm{yrs}$. The average age of the patients was 33.88 yrs (Table 2 and Figure 2). 
Table 2: Age distribution of patients

\begin{tabular}{|c|c|c|}
\hline Age group in years & Number of patients & Percentage (\%) \\
\hline $0-10$ & 0 & 6 \\
\hline $11-20$ & 3 & 28 \\
\hline $21-30$ & 14 & 40 \\
\hline $31-40$ & 20 & 12 \\
\hline $41-50$ & 6 & 2 \\
\hline $51-60$ & 6 & 0 \\
\hline $61-70$ & 1 & $\mathbf{1 0 0}$ \\
\hline $71-80$ & 0 & 2 \\
\hline
\end{tabular}

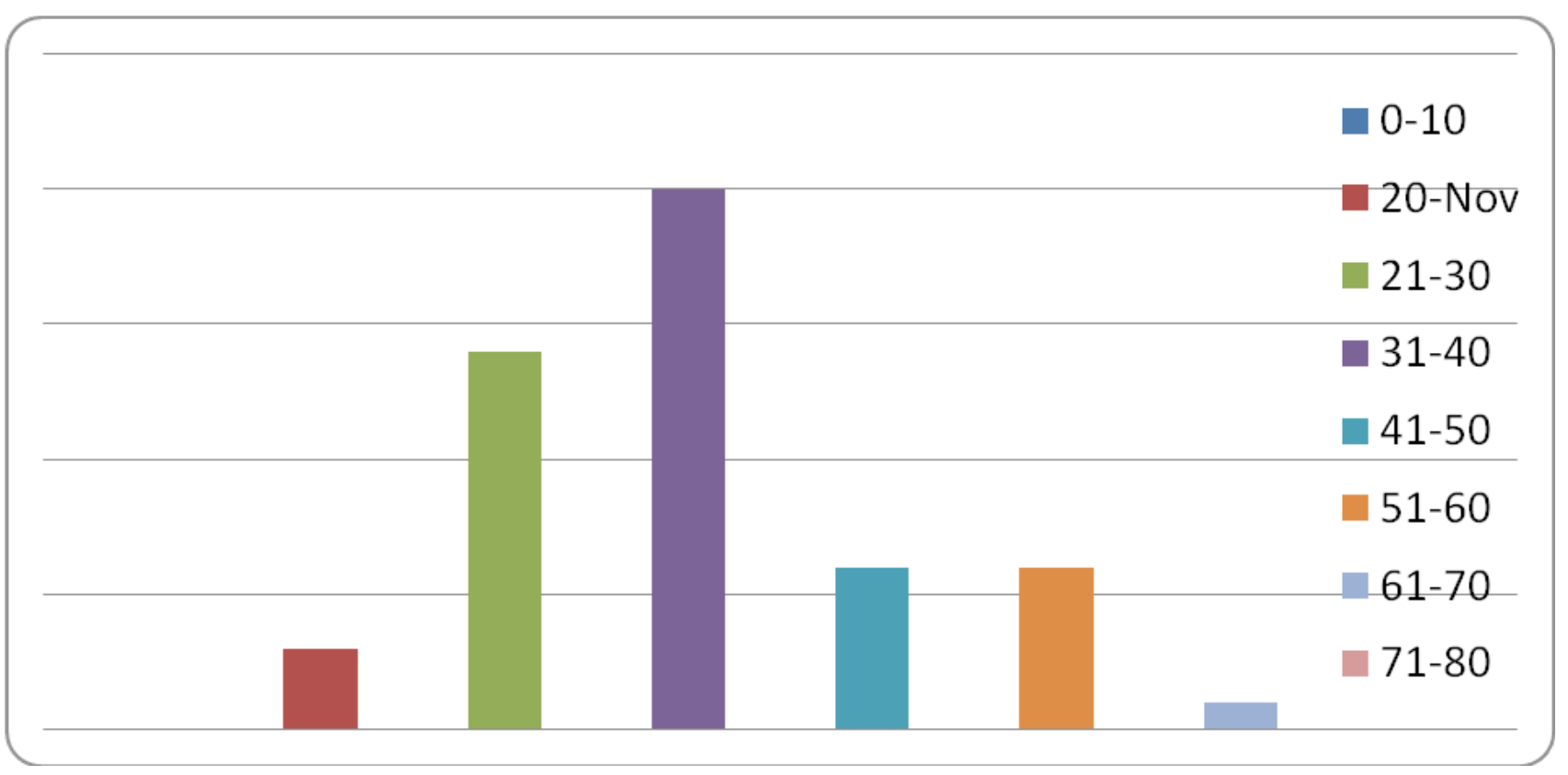

Figure 2 Age distribution of patients

Location of patients: From Table 3, it is seen that most of the patients (76\%) are from a rural area and Brahmaputra Valley. Details are narrated in Table 3.

Table 3: Location of the patients

\begin{tabular}{|l|c|c|}
\hline Residence & Number of patients & Percentage (\%) \\
\hline Urban & 12 & 24 \\
\hline Rural & 38 & 76 \\
\hline & Total 50 & $\mathbf{1 0 0}$ \\
\hline
\end{tabular}

Occupational status of patients: Majority of the female patients not having any definite occupation and they were an aid to engaged in household works as shown in Table 4. 
Table 4 Occupational status of patients

\begin{tabular}{|l|c|c|}
\hline Occupation & Number of patients & Percentage (\%) \\
\hline Minor & 3 & 6 \\
\hline House-wife & 30 & 60 \\
\hline Cultivator & 3 & 6 \\
\hline Student & 2 & 4 \\
\hline Businessman & 3 & 6 \\
\hline Service & 9 & 18 \\
\hline & Total 50 & $\mathbf{1 0 0}$ \\
\hline
\end{tabular}

Consistency of thyroid swelling: The clinical impression of 50 thyroid nodule under study were solid were 29 cases and 8 cystic and rest were 13 were of mixed consistency as shown in Table $\mathbf{5}$.

Table 5 Consistency of thyroid swelling

\begin{tabular}{|l|c|c|}
\hline Consistency & Number of patients & Percentage (\%) \\
\hline Solid & 29 & 58 \\
\hline Cystic & 8 & 16 \\
\hline Mixed & 13 & 26 \\
\hline
\end{tabular}

\section{Discussion}

Evaluation of thyroid pathology is one of the most common problems encountered in day today medical practice and the brunt of its diagnosis is falls on ENT and Head \& Neck surgeon. Almost affecting the thyroid like degenerative diseases, hyperthyroidism, thyroiditis, a benign or malignant tumour can present as a circumscribed or diffuse swelling. Moreover, most of the patient are female so we have to take care of proper cosmetic. We should also try to preserve the normal function of thyroid for all cases in the rest of the life postoperatively.

In the present study, there was a preponderance of this disease entity towards female $70 \%$ as compared to male counterpart $30 \%$. This can be explained by the increasing demand for iodine in females. Male to female ratio is found $1: 2.5$, whereas, in most of the western series, the ratio being reported as 1.1.53. These findings are in agreement with the finding of Mazzaferri EL. $8,9,10$

In our study, the average age is 38years. In males, the mean age was 39.4years and females 30years. MC Gershengorn et al. ${ }^{13}$ also reported a mean age of 39 in male and 35yrs in females respectively which agree with the current results.

Most of the patient in our study hailed from the rural area and since females outnumbered male and as the majority of female did not have any specific occupation and they are busy with their household work, maybe a factor of higher age incidence.

Ethical Clearance: Taken.

Source of Funding: None.

Conflict of Interest: None.

\section{References}

1. Chaudhary V, Bano S. Imaging of the thyroid: Recent advances. Indian J EndocrMetab 2012;16:371-6.

2. Mazzaferri E. Management of a solitary thyroid nodule. N Engl J Med 1993;328:553-559.

3. Carroll B. Asymptomatic thyroid nodules: incidental sonographic detection. AJR Am J Roentgenol 1982;138:499-501.

4. Woestyn J, Afschrift M, Schelstraete K, Vermeulen A. Demonstration of nodules in the normal thyroid by echography. Br J Radiol 1985;58:1179-1182.

5. Brander A, Viikinkoski V, Nickels J, Kivisaari L. Importance of thyroid abnormalities detected at US screening: a 5-year follow-up. Radiology 2000;215:801-806.

6. Mortenson J, Woolner L, Bennett W. Gross and microscopic findings in clinically normal thyroid glands. J ClinEndocrinolMetab 1955;15:12701280. 
7. Nikita Jain, Parthiv Brahmbhatt, Chandra Ray Chaudhuri, Aman Singhal. Ultrasonography of Thyroid Lesions with Clinicopathological Correlation. International Journal of Research and Review 2020;7(1):142-158.

8. Mazzaferri EL. Management of a solitary thyroid nodule. N Engl J Med. 1993;328(8):553-9.

9. Kung AW, Chau MT, Lao TT, et al. The effect of pregnancy on thyroid nodule formation. J Clin Endocrinol Metab 2002;87(3):1010-4.

10. Struve $\mathrm{CW}$, Haupt $\mathrm{S}$, Ohlen S. Influence of frequency of previous pregnancies on the prevalence of thyroid nodules in women without clinical evidence of thyroid disease. Thyroid 1993;3(1):7-9.
11. DeGroot LJ. Clinical review 2: diagnostic approach and management of patients exposed to irradiation to the thyroid. J Clin Endocrinol Metab 1989;69(5):925-8.

12. Antonelli A, Silvano G, Bianchi F, et al. Risk of thyroid nodules in subjectsoccupationally exposed to radiation: a cross-sectional study. Occup Environ Med 1995;52(8):500-4.

13. M C Gershengorn, R E Lippoldt, H Edelhoch, J Robbins. Structure and stability of human thyroxine-binding globulin. Biol Chem 1977 Dec 10;252(23):8719-23. 